\title{
Phase I study of celecoxib with concurrent irinotecan, cisplatin, and radiation therapy for patients with unresectable locally advanced non-small cell lung cancer
}

\author{
Ritsuko Komaki ${ }^{1}{ }^{*}, X_{i o n g} W_{e i}{ }^{1}$, Pamela K. Allen ${ }^{1}$, Zhongxing Liao ${ }^{1}$, Luka Milas ${ }^{1}$, James D. Cox ${ }^{1}$, \\ Michael S. O'Reilly ${ }^{1}$, Joe Y. Chang ${ }^{1}$, Mary Frances McAleer ${ }^{1}$, Melenda Jeter ${ }^{1}$, George R. Blumenschein Jr. $^{2}$ \\ and Merrill S. Kies ${ }^{2}$
}

${ }^{1}$ Department of Radiation Oncology, The University of Texas MD Anderson Cancer Center, Houston, TX, USA

${ }^{2}$ Department of Thoracic/Head and Neck Medical Oncology, The University of Texas MD Anderson Cancer Center, Houston, TX, USA

\section{Edited by:}

Masahiro Tsuboi, Kanagawa Cancer Center, Japan

Reviewed by:

Arnold Manfred Herskovic, Rush University Medical Center, USA Rabab Mohamed Gaafar, Cairo University, Egypt

Lorenzo Spaggiari, European Institute of Oncology, Italy

\section{${ }^{*}$ Correspondence:}

Ritsuko Komaki, Department of Radiation Oncology, Unit 97, The University of Texas MD Anderson Cancer Center, 1515 Holcombe Blvd, Houston, TX 77030, USA

e-mail: rkomaki@mdanderson.org
Purpose: Preclinical findings suggest that adding targeted therapies to combination radiation-chemotherapy can enhance treatment efficacy; however, this approach may enhance normal tissue toxicity. We investigated the maximum tolerated dose, dose-limiting toxicities, and response rate when the selective cyclooxygenase-2 inhibitor celecoxib is added to concurrent irinotecan, cisplatin, and radiation therapy for patients with inoperable stage II-III non-small cell lung cancer (NSCLC). Methods and Materials: Eighteen patients were analyzed in a phase I clinical dose-escalation trial. Celecoxib was given daily beginning 5 days before radiation followed by maintenance doses for 12 weeks. Toxicity was graded with the Common Terminology Criteria for Adverse Events V3.0 and response with the World Health Organization system. Primary endpoints were maximum tolerated dose of celecoxib and treatment toxicity; secondary endpoints were response and survival rates. Results: The maximum tolerated dose of celecoxib was not reached, in part owing to discontinuation of the drug supply. At doses of 200 or $400 \mathrm{mg} /$ day, no patients experienced any dose-limiting toxicity (acute grade $\geq 4$ esophagitis or pneumonitis, neutropenic fever or thrombocytopenia requiring transfusion, or acute grade $\geq 3$ diarrhea). Grade 3 toxicities were leukopenia (five patients), fatigue (3), pneumonitis (2), dyspnea (1), pain (1), and esophageal stricture (1). Interestingly, pulmonary fibrosis (a late toxicity) was no more severe in the higher-dose (400-mg) group and may have been less common than in the lower-dose group. The clinical response rate was 100\% (8 complete, 10 partial). Two-year rates were: overall survival 65\%; local-regional control 69\%; distant metastasis-free survival $71 \%$; and disease-free survival $64 \%$. Conclusion: Although preliminary, our results suggest that adding celecoxib to concurrent chemoradiation for inoperable NSCLC is safe and can improve outcome without increasing normal tissue toxicity.

Keywords: celebrex, CPT-11, cyclooxygenase-2 inhibitor, concurrent chemoradiotherapy, stage II or III non-small cell lung cancer

\section{INTRODUCTION}

Lung cancer is a major cause of cancer-related mortality worldwide (Jemal et al., 2011), with 5-year survival rates of only about $16 \%$. Roughly one-third of non-small cell lung cancer (NSCLC) presents as locally advanced disease, with tumor or nodal involvement of the mediastinum. Because disease at this stage is often not resectable, definitive treatment that combines platinum-based chemotherapy and radiation therapy is considered the standard of care (Furuse et al., 1999; Pfister et al., 2004; Blackstock and Govindan, 2007), particularly for patients with good performance status. However, the optimal schedule and components of chemoradiotherapy regimens are still being explored, and the 5-year survival rates still leave considerable room for improvement.

Concurrent chemoradiation seems to be more effective than sequential therapy, as demonstrated by the West Japan Lung Group (Furuse et al., 1999), the Radiation Therapy Oncology
Group (RTOG) in trial 94-10 (Curran et al., 2011), and the French NPC-9501 trial (Fournel et al., 2005). However, these trials used older chemotherapy agents (e.g., vindesine, vinblastine, etoposide), whereas more recent regimens that combine platinumbased chemotherapy with other agents (e.g., docetaxel, paclitaxel, irinotecan, gemcitabine, vinorelbine) seem to be more effective for advanced NSCLC (Kubota et al., 2004; Baggstrom et al., 2007). However, the newer chemotherapy agents must be administered in reduced doses in combination with thoracic radiation therapy to avoid producing unacceptable toxicity.

One such agent being studied in combination with platinumbased chemotherapy and radiation is irinotecan (CPT-11), a topoisomerase I inhibitor with radiosensitizing effects (Tamura et al., 1997). Irinotecan is thought to have synergistic effects with cisplatin in NSCLC (Yamada et al., 2002; Takiguchi et al., 2005; Kim et al., 2006). Several trials of irinotecan, cisplatin, and radiation 
for locally advanced NSCLC (Takiguchi et al., 2005; Langer et al., 2007) have shown that this combination has promise but is limited by both acute toxicity, particularly esophagitis and pneumonitis, and late toxicity, mostly diarrhea. These effects may be related to increases in tissue prostaglandin $\mathrm{E}_{2}\left(\mathrm{PGE}_{2}\right)$ levels; Trifan et al. (2002) reported that both cyclooxygenase-2 (COX-2) and $\mathrm{PGE}_{2}$ protein levels were increased after irinotecan in mouse and rat models and that the selective COX-2 inhibitor celecoxib enhanced the antitumor effect while blunting late diarrhea in these models. Overexpression of COX-2 in lung cancer is associated with aggressive tumor growth, facilitation of metastatic spread, and poor patient survival (Achiwa et al., 1999; Khuri et al., 2001; Liao et al., 2005). If inhibiting this enzyme with COX-2 inhibitors can enhance tumor radioresponse without appreciably increasing radiation-induced normal tissue damage, then COX-2 inhibitors could increase the therapeutic ratio of radiation therapy (Komaki et al., 2004).

We hypothesized that combining celecoxib with irinotecan, cisplatin, and radiation therapy would have the dual benefit of enhancing antitumor effects and reducing toxicity and thus could improve outcome for patients with unresectable NSCLC. We describe here the findings from a phase I study of a novel regimen combining celecoxib with irinotecan, cisplatin, and radiation therapy for patients with unresectable stage II-III NSCLC.

\section{MATERIALS AND METHODS}

This phase I prospective clinical trial was approved by the appropriate institutional review board of The University of Texas MD Anderson Cancer Center, and all patients provided written informed consent before participating. A total of 20 patients with inoperable stage II or III NSCLC were enrolled beginning in November 2003. Inoperability, whether medical or disease-related, was determined jointly by a group of thoracic surgeons, thoracic radiation oncologists, and medical thoracic oncologists at MD Anderson. In most cases, stage II or IIIA disease was inoperable for medical reasons and stage IIIB disease was inoperable owing to tumor proximity to critical structures.

\section{ELIGIBILITY CRITERIA}

Inclusion criteria were as follows: histologic or cytologic evidence of NSCLC; unresectable stage II or III disease; good performance status (Karnofsky score $\geq 70$ ); age $18-70$ years; no prior radiation or combined-modality therapy for other malignancy; no evidence of distant metastatic disease; and adequate end-organ indices [i.e., absolute neutrophil count $\geq 2,000 / \mu \mathrm{L}$, platelet count $\geq 100,000 / \mu \mathrm{L}$, serum creatinine level $\leq 1.5 \mathrm{mg} / \mathrm{dL}$, total bilirubin $\leq 1.5 \times$ institutional upper limit of normal (1.0 IU/L), and aspartate aminotransferase levels $\leq 1.5 \times$ institutional upper limit of normal $(46 \mathrm{IU} / \mathrm{L})]$. Prior chemotherapy was allowed if it had been completed at least 4 weeks before study entry. Use of low-dose aspirin $(<200 \mathrm{mg} /$ day $)$ was allowed, but regular use of highdose aspirin ( $>2 \mathrm{~g} /$ day) or other non-steroidal anti-inflammatory drugs was not.

Exclusion criteria were history of gastric ulcer, gastrointestinal bleeding, or renal failure; history of poorly controlled hypertension (systolic $>150 \mathrm{mmHg}$ ), angina, or other cardiac abnormalities; history of cardiovascular disease (e.g., myocardial infarction, angina, coronary angioplasty, congestive heart failure, stroke, or coronary bypass surgery in the past 6 months); family history of premature coronary disease (i.e., onset $<55$ years); receipt of amifostine within the past 6 months; history of active, invasive malignancies curatively treated in the past 2 years; allergies to sulfonamides, non-steroidal anti-inflammatory drugs, or celecoxib; uncontrolled hypercholesteremia (low-density lipoprotein cholesterol levels of $>200 \mathrm{mg} / \mathrm{dL}$ more than twice in repeated tests); history of deep venous thrombosis, pulmonary embolism, or systemic lupus erythematosus; family history of protein S or C deficiencies; and prior heparin-induced thrombocytopenia, factor $\mathrm{V}$ Leiden deficiencies, or high homocysteine levels.

\section{ENDPOINT, DOSE ESCALATION, AND DOSE-LIMITING TOXICITY}

The phase I endpoint (the maximum tolerated dose of celecoxib combined with fixed-dose irinotecan and cisplatin plus radiation) was to be determined by standard dose escalation in 10-patient cohorts. Ten patients were to be entered at each dose level beginning at $200 \mathrm{mg} /$ day. Enrollment in the higher-dose groups was to be terminated of $\geq 5$ patients had grade $\geq 3$ esophagitis or pneumonitis. If $\leq 4$ patients showed grade $\geq 3$ esophagitis or pneumonitis, 10 patients were to be entered at the next higher-dose level.

Adverse events were defined according to the Common Terminology Criteria for Adverse Events v3.0 (National Cancer Institute, 2006). Dose-limiting toxicities were acute neutropenic fever (temperature $>100.6^{\circ} \mathrm{F}$ with absolute neutrophil count $\left.<1,000 / \mu \mathrm{L}\right)$; acute thrombocytopenia requiring transfusion; acute grade $\geq 4$ esophagitis or pneumonitis; acute grade $\geq 3$ diarrhea; and any treatment-related grade 5 toxicity. The maximum tolerated dose was defined as 1 dose level below that causing any dose-limiting toxicity.

\section{TREATMENT}

The treatment schema is shown in Figure 1. Radiation therapy was started after 5 days of celecoxib and given in 1.8-Gy daily fractions, 5 fractions/week, for 7 weeks (total dose $63 \mathrm{~Gy}$ in 35 fractions). The gross tumor volume included the complete extent of visible primary tumor and lymph nodes visualized on radiography. Clinical target volume encompassed the gross tumor volume plus a margin of $8 \mathrm{~mm}$, and the planning target volume encompassed the clinical target volume plus a margin of at least $7 \mathrm{~mm}$ but no more than $13 \mathrm{~mm}$. The supraclavicular fossa was not included in the treatment field unless the primary tumor was located in the upper lobe or a supraclavicular node was clinically involved. The ipsilateral hilar lymph nodes (with a $1.5-\mathrm{cm}$ margin) and the contralateral hilar lymph nodes (with a $1-\mathrm{cm}$ margin) were routinely included in the radiation fields. Three-dimensional conformal or intensity-modulated radiotherapy treatment planning was used in all cases, and radiation doses were prescribed to an isodose line covering $95 \%$ of the planning target volume with no lung heterogeneity correction. The radiation beam energy was defined by the optimized treatment plan.

Irinotecan was administered once a week for 7 weeks (on day 1 of weeks 2-8) at $30 \mathrm{mg} / \mathrm{m}^{2}$ as a 90 -min intravenous infusion before the cisplatin. Cisplatin was administered once a week for 
7 weeks (weeks 2-8) at $25 \mathrm{mg} / \mathrm{m}^{2}$ as a $60-\mathrm{min}$ intravenous infusion. Hydration included at least $1 \mathrm{~L}$ of intravenous fluids before the cisplatin infusion, plus at least 1 additional liter of fluid with mannitol and appropriate electrolytes afterward. Celecoxib was given orally [ 10 patients at $200 \mathrm{mg} /$ day and 10 at $400 \mathrm{mg} /$ day $(200 \mathrm{mg}$, twicedaily)] beginning 5 days before the chemoradiation; the same dose was continued throughout the 8-week course of chemoradiation therapy and for four more weeks thereafter (through week 12).

\section{BASELINE AND FOLLOW-UP EVALUATIONS}

Baseline evaluations included complete medical history and physical examination, with documentation of Karnofsky performance status, recent weight loss, usual weight, and concurrent nonmalignant diseases and therapies. Laboratory studies were done before registration and included complete blood counts; blood chemistries; alanine aminotransferase levels; and urinalysis. Imaging studies were to be obtained within 6 weeks before study registration and included chest X-ray, computed tomography (CT) of the chest (including upper abdomen), magnetic resonance imaging of the brain, positron emission tomography, and radionuclide bone scanning as needed. Patients suspected of having gastrointestinal bleeding underwent esophagogastroduodenoscopy. All patients underwent pulmonary function tests and electrocardiography before treatment. The location, type, and size of all measurable lesions were documented before treatment.

Patients were assessed weekly during radiation therapy, with interval history and physical examinations, with particular attention to drug-induced side effects and changes in body weight and performance status; laboratory tests were also performed weekly. Blood chemistry was assessed as needed to define drug toxicity, and esophagogastroduodenoscopy was used when clinically indicated. Tumor measurements, response of each lesion, site, and overall response were documented before and 1 month after the entire course of therapy had been completed. Patients were required to fill out medication diaries to assess compliance.

\section{RESPONSE CRITERIA}

Tumor response was evaluated according to World Health Organization criteria (Miller et al., 1981), in which tumors were measured in two dimensions on chest X-rays, CT scans, or sonograms and their area estimated as the product of the longest diameter and its perpendicular dimension. Complete response was the disappearance of all clinical evidence of tumor that persisted for at least 4 weeks; partial response as a decrease in the sum of the areas of all measured lesions of $>50 \%$ that persisted for at least 4 weeks. Regression of lesions not fulfilling the criteria of partial response but without evidence of progression was considered stable disease. Progressive disease was any increase exceeding 25\% in the areas of any measurable lesion or the appearance of new lesions (including brain lesions). Response durations were measured from the time of response (not the beginning of treatment) until evidence of progressive disease appeared. Survival duration was measured from the day of registration to the date of last follow-up or documented death. Patterns of failure were assessed from the day of registration to the date of the first documented failure.

\section{STATISTICAL METHODS}

Pearson's chi-square tests were used to assess associations between acute normal tissue toxicity or late normal tissue toxicity and celecoxib dose in frequency tables. Overall survival was measured from the date of NSCLC diagnosis to the date of last follow-up or documented death. Kaplan-Meier survival estimates were used to calculate survival distributions and log-rank tests to assess quality of survival function. $P$ values $\leq 0.05$ were considered to indicate statistically significant differences for all two-sided statistical tests. All analyses were done with Stata statistical software (Release 10, 2007; StataCorp LP, College Station, TX, USA).

\section{RESULTS}

Twenty patients with unresectable NSCLC (2 stage II and 17 stage III) were enrolled over a 4 -year period. The median follow-up time was 25.3 months (range, 7.0-60.4 months). Two patients [both in the lower-dose $(200 \mathrm{mg}$ ) celecoxib group] withdrew from the study after the first weekly dose of irinotecan, one after experiencing an abdominal rash that spread to both breasts and thighs and the other after severe chest pain, nausea, and vomiting requiring inpatient intravenous rehydration. The other 18 patients completed the protocol treatment and were eligible for analysis. The trial was stopped early in September 2008 because of slow accrual owing to publication of three randomized trials demonstrating increased

\begin{tabular}{|c|c|c|c|c|c|c|c|c|c|}
\hline & Week 1 & Week 2 & Week 3 & Week 4 & Week 5 & Week 6 & Week 7 & Week 8 & $\begin{array}{c}\text { Weeks } \\
\text { 9-12 }\end{array}$ \\
\hline Celecoxib & ccccc & ccccccc & ccccccc & ccccecc & ccccccc & ccccccc & ccccccc & ccccccc & ccceccc \\
\hline Radiation & & $x x x x x$ & $x x x x x$ & $\operatorname{xxxxx}$ & $x x x x x$ & $\operatorname{xxxxx}$ & $\operatorname{xxxxx}$ & $\operatorname{xxxxx}$ & \\
\hline Irinotecan & & I & I & I & I & I & I & I & \\
\hline Cisplatin & & C & C & C & $\mathrm{C}$ & C & C & C & \\
\hline
\end{tabular}

FIGURE 1 | Treatment schema. Radiation therapy was started after 5 days of celecoxib. Cisplatin and irinotecan were administered once a week for 7 weeks (weeks 2-8). Celecoxib was given orally beginning 5 days before the initiation of chemoradiation therapy; the same dose was continued daily throughout the entire 8-week course of chemoradiation therapy and for four more weeks thereafter (through week 12). 


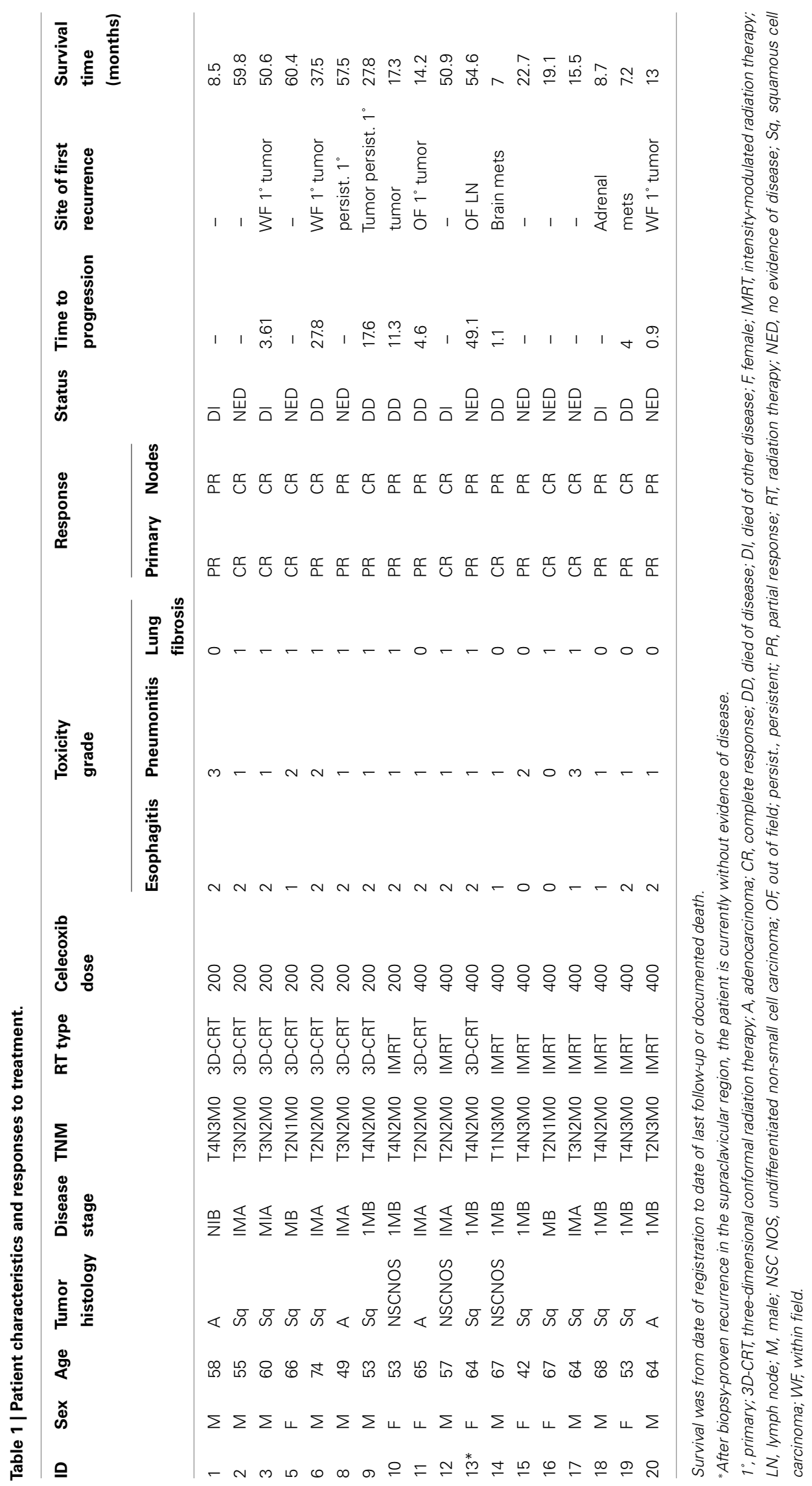


cardiac toxicity from another selective COX-2 inhibitor, rofecoxib (Vioxx), and the withdrawal of that drug from the market. As a result, no patients were enrolled in a planned 800-mg dose group (the maximum allowable dose according to the U.S. Food and Drug Administration). Characteristics of the 18 eligible patients are shown in Table 1 . The median patient age was 62 years (range, 42-74 years); 4 (22\%) had adenocarcinomas, 11 (61\%) squamous cell carcinomas, and 3 (17\%) unspecified NSCLC.

\section{TOXICITY}

Eighteen patients were evaluable for toxic effects (Table 2). Pulmonary toxicity was diagnosed by thoracic radiologists who were blinded as to treatment group, and the diagnosis was subsequently confirmed by radiation oncologists with the isodose curves. No patient experienced grade 4 toxicity or dose-limiting toxicity; hence the maximum tolerated dose was not reached. No patient experienced grade $\geq 3$ treatment-related esophagitis; two patients (11\%) had grade 3 pneumonitis. No differences in these toxic effects were noted between celecoxib dose groups $(P>0.05)$. Similarly, the incidence of grade 3 leukopenia was no different between groups (three in the 200-mg group and two in the 400-mg group, $P=0.25$ ). However, pulmonary fibrosis (assessed on chest CT scans and diagnostic image reports) was worse in the lower-dose group [one grade 0 and seven grade 1 in the 200-mg group vs. six grade 0 and four grade 1 in the $400-\mathrm{mg}$ group $(P=0.04)]$.

\section{EFFICACY}

Tumor response, although not the primary endpoint, was evaluable in 18 patients: 7 had complete response and 11 had partial response of the primary lung tumor; 9 patients had complete response and 9 partial response of nodal lymphadenopathy. Tumor response rates were not significantly different between the two dose groups $(P>0.05)$.

\section{TUMOR CONTROL AND SURVIVAL}

Treatment outcomes are shown in Figure 2. The median overall survival time for all 18 patients was 37.5 months (range, 7.0-60.4 months). At 2 years, rates for all 18 patients were as follows: overall survival 65\%; local-regional control 69\%; distant metastasis-free survival 71\%; and disease-free survival $64 \%$. Patients in the two celecoxib dose groups did not differ in median overall survival time (37.5 months for the 200-mg group vs. 50.9 months for the 400-mg group, $P>0.05)$, 2-year overall survival rate $(75 \%$ for $200 \mathrm{mg}$ vs. $58 \%$ for $400 \mathrm{mg}, P>0.05)$, localregional control rate $(71 \% 200 \mathrm{mg}$ vs. $70 \% 400 \mathrm{mg}, P>0.05)$, distant metastasis-free survival rate $(86 \% 200 \mathrm{mg}$ vs. $60 \% 400 \mathrm{mg}$, $P>0.05)$, or disease-free survival rate $(71 \% 200 \mathrm{mg}$ vs. $60 \%$ $400 \mathrm{mg}, P>0.05)$.

\section{DISCUSSION}

The combination of radiation and chemotherapy for lung cancer has been shown to improve tumor response rates $(84 \%$ for concurrent chemoradiation therapy vs. $66 \%$ for radiation alone; Furuse et al., 1999), 3-year survival rates (29.7\% for weekly paclitaxel vs. $16.8 \%$ for radiation alone; Huber et al., 2006), and 5-year survival rates $(8.2 \%$ for concurrent chemoradiation therapy vs. $6.0 \%$ for radiation alone; Auperin et al., 2006). Preclinical findings suggest that molecular targeted therapies can enhance efficacy when used in combination with other treatment modalities; however, whether such therapies would enhance normal tissue toxicity has been unclear.

The primary goal of this phase I study was to determine the maximum tolerated dose of celecoxib given in combination with irinotecan, cisplatin, and thoracic radiation; secondary goals were to determine the feasibility of this therapy in terms of its toxicity profile and its effectiveness. We found that celecoxib can be safely administered in doses up to $400 \mathrm{mg}$ in this combination for

Table 2 | Acute and late toxic effects of patients given 200 or $\mathbf{4 0 0} \mathbf{m g}$ celecoxib with chemoradiation therapy for non-small cell lung cancer.

\begin{tabular}{|c|c|c|c|c|c|c|c|c|c|c|c|}
\hline \multirow[t]{3}{*}{ Toxic effect } & \multicolumn{10}{|c|}{ Celecoxib dose group } & \multirow[t]{3}{*}{$P$ value } \\
\hline & \multicolumn{5}{|c|}{ Toxicity grade 200 mg/day } & \multicolumn{5}{|c|}{ Toxicity grade $400 \mathrm{mg} / \mathrm{day}$} & \\
\hline & 0 & 1 & 2 & 3 & 4 & 0 & 1 & 2 & 3 & 4 & \\
\hline Pneumonitis & 0 & 5 & 4 & 1 & 0 & 1 & 7 & 1 & 1 & 0 & 0.69 \\
\hline Esophagitis & 0 & 1 & 7 & 0 & 0 & 2 & 3 & 5 & 0 & 0 & 0.21 \\
\hline Radiation dermatitis & 0 & 4 & 4 & 0 & 0 & 1 & 5 & 4 & 0 & 0 & 0.64 \\
\hline Pericardial effusion & 7 & 1 & 0 & 0 & 0 & 10 & 0 & 0 & 0 & 0 & 0.31 \\
\hline Fatigue & 0 & 2 & 6 & 0 & 0 & 2 & 0 & 6 & 2 & 0 & 0.12 \\
\hline Dyspnea & 5 & 2 & 0 & 1 & 0 & 9 & 0 & 1 & 0 & 0 & 0.17 \\
\hline Pain & 4 & 1 & 2 & 1 & 0 & 9 & 0 & 1 & 0 & 0 & 0.09 \\
\hline Nausea & 4 & 3 & 1 & 0 & 0 & 6 & 3 & 1 & 0 & 0 & 0.91 \\
\hline Pulmonary fibrosis & 1 & 7 & 0 & 0 & 0 & 6 & 4 & 0 & 0 & 0 & 0.04 \\
\hline Esophageal stricture & 8 & 0 & 0 & 0 & 0 & 8 & 1 & 0 & 1 & 0 & 0.41 \\
\hline Anemia & 3 & 4 & 1 & 0 & 0 & 5 & 3 & 1 & 1 & 0 & 0.67 \\
\hline Leukopenia & 4 & 1 & 0 & 3 & 0 & 5 & 0 & 3 & 2 & 0 & 0.25 \\
\hline Thrombocytopenia & 7 & 1 & 0 & 0 & 0 & 7 & 1 & 2 & 0 & 0 & 0.41 \\
\hline
\end{tabular}

Bold indicates that the $P$ value is less than 0.05 . 

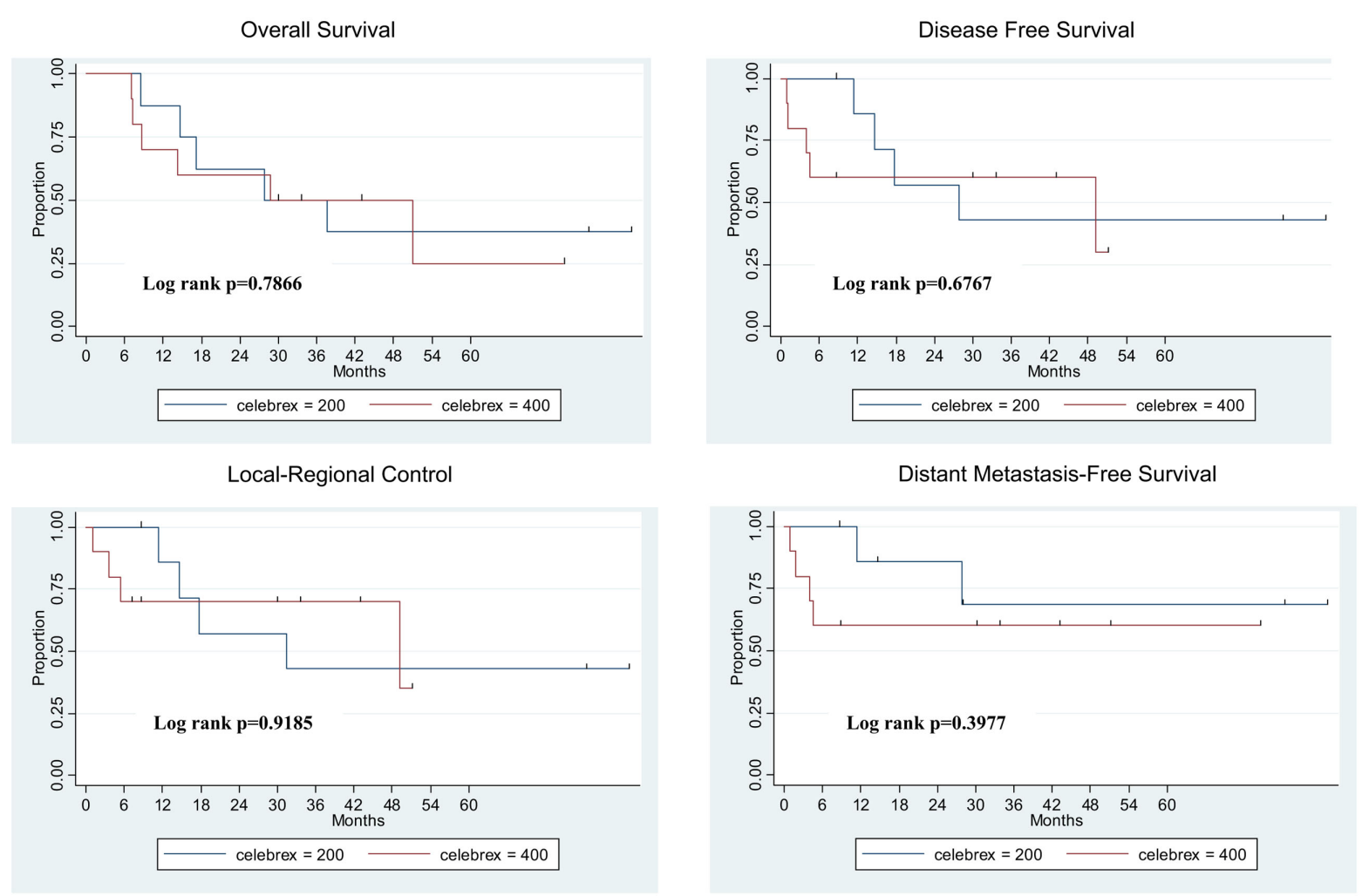

FIGURE 2 | Treatment outcomes for $\mathbf{1 8}$ eligible patients. Survival duration was measured from the day of registration to the date of last follow-up or documented death. Failure was measured from the day of registration to the date of first documented failure event.

patients with unresectable stage II or III NSCLC. No patients developed treatment-related cardiac problems, diarrhea, or neutropenic fever. No patients developed treatment-related grade $\geq 3$ acute thrombocytopenia or anemia requiring transfusion. One patient in each celecoxib dose group ( 200 or $400 \mathrm{mg} /$ day) developed grade 3 pneumonitis, which could have resulted from the radiation, the drug therapy, or both. No patients experienced any grade 4 toxicity. The most common grade 3 toxicity was leukopenia (three patients in the low-dose group and two in the higher-dose group), but this could also be attributable to concurrent chemotherapy. Hence we found no evidence of increased normal tissue toxicity from the addition of celecoxib - indeed, esophagitis and pneumonitis were no worse in the higher-dose (400 mg) group. The apparent difference in lung fibrosis between groups, with the lower-dose group experiencing more fibrosis, needs to be verified in a larger-scale phase II or III trial. Nevertheless, these findings compare quite favorably with results of a phase II study indicating no improvement in side effects from the addition of celecoxib to second-line therapy (Lilenbaum et al., 2006).

The response rates in this study (44\% complete, $56 \%$ partial) were higher than those in studies by Mutter et al. (2009; 7\% complete and 36\% partial) and Altorki et al. (2003; 17\% complete and $48 \%$ partial). We are reluctant to speculate as to why this is the case given the very small number of patients in our study and the fact that tumor response was not a primary endpoint. However, our chemotherapy regimen (cisplatin and irinotecan) was different that that of these other studies (carboplatin and paclitaxel), and patients in these other studies may have had bulkier tumors or poorer performance status than ours did. We further recognize that tumor response is more commonly assessed with RECIST than with the WHO criteria, which was the institutional policy at the time; however, our response rates would have been still higher if we had used the RECIST system. Moreover, the 2-year overall survival rate in our study, 69\%, was also excellent compared with other trials of combined chemoradiotherapy such as RTOG 9801 (Movsas et al., 2005) and RTOG 94-10 (Curran et al., 2011).

We conclude that adding celecoxib to weekly irinotecan and cisplatin with concurrent thoracic radiation therapy for unresectable stage IIB or III NSCLC is safe, feasible, and may improve outcomes. Further randomized phase II trials are needed to determine the clinical significance of celecoxib and pulmonary fibrosis, and a prospective randomized phase III trial is needed to definitively determine if adding a COX-2 inhibitor such as celecoxib to chemoradiation therapy will produce a survival benefit for patients with unresectable stage IIB or III NSCLC.

\section{ACKNOWLEDGMENTS}

We are deeply appreciative of the efforts of Christine F. Wogan, MS, ELS, of MD Anderson's Division of Radiation Oncology, in developing this manuscript. This work was supported by the National Comprehensive Cancer Network, Pfizer, Inc., and National Cancer Institute grants CA06294 and CA016672. This work was presented in part at the 91st annual meeting of the American Radium Society, Vancouver, BC, Canada, April 25-29, 2009. 


\section{REFERENCES}

Achiwa, H., Yatabe, Y., Hida, T., Kuroishi, T., Kozaki, K., Nakamura, S., Ogawa, M., Sugiura, T., Mitsudomi, T., and Takahashi, T. (1999). Prognostic significance of elevated cyclooxygenase 2 expression in primary, resected lung adenocarcinomas. Clin. Cancer Res. 5, 1001-1005.

Altorki, N. K., Keresztes, R. S., Port, J. L., Libby, D. M., Korst, R. J., Flieder, D. B., Ferrara, C. A., Yankelevitz, D. F., Subbaramaiah, K., Pasmantier, M. W., and Dannenberg, A. J. (2003). Celecoxib, a selective cyclooxygenase- 2 inhibitor, enhances the response to preoperative paclitaxel and carboplatin in early-stage nonsmall-cell lung cancer. J. Clin. Oncol. 21, 2645-2650.

Auperin, A., Le Pechoux, C., Pignon, J. P., Koning, C., Jeremic, B., Clamon, G., Einhorn, L., Ball, D., Trovo, M. G., Groen, H. J., Bonner, J. A., Le Chevalier, T., Arriagada, R., and MetaAnalysis of Cisplatin/Carboplatin Based Concomitant Chemotherapy in Non-Small Cell Lung Cancer (MAC3-LC) Group. (2006). Concomitant radio-chemotherapy based on platin compounds in patients with locally advanced non-small cell lung cancer (NSCLC): a metaanalysis of individual data from 1764 patients. Ann. Oncol. 17, 473-483.

Baggstrom, M. Q., Stinchcombe, T. E., Fried, D. B., Poole, C., Hensing, T. A., and Socinski, M. A. (2007). Thirdgeneration chemotherapy agents in the treatment of advanced non-small cell lung cancer: a meta-analysis. J. Thorac. Oncol. 2, 845-853.

Blackstock, A. W., and Govindan, R. (2007). Definitive chemoradiation for the treatment of locally advanced non small-cell lung cancer. J. Clin. Oncol. 25, 4146-4152.

Curran, W. J. Jr., Paulus, R., Langer, C. J., Komaki, R., Lee, J. S., Hauser, S., Movsas, B., Wasserman, T., Rosenthal, S. A., Gore, E., Machtay, M., Sause, W., and Cox, J. D. (2011). Sequential vs concurrent chemoradiation for stage iii non-small cell lung cancer: randomized phase III trial RTOG 9410. J. Natl. Cancer Inst. 103, 1452-1460.

Fournel, P., Robinet, G., Thomas, P., Souquet, P. J., Léna, H., Vergnenégre, A., Delhoume, J. Y., Le Treut, J., Silvani, J. A., Dansin, E., Bozonnat, M. C., Daurés, J. P., Mornex, F., and Pérol, M. (2005). Randomized phase III trial of sequential chemoradiotherapy compared with concurrent chemoradiotherapy in locally advanced non-small-cell lung cancer: Groupe Lyon-Saint-Etienne
d'Oncologie Thoracique-Groupe Francais de Pneumo-Cancerologie NPC 95-01 Study. J. Clin. Oncol. 23, 5910-5917.

Furuse, K., Fukuoka, M., Kawahara, M., Nishikawa, H., Takada, Y., Kudoh, S., Katagami, N., and Ariyoshi, Y. (1999). Phase III study of concurrent versus sequential thoracic radiotherapy in combination with mitomycin, vindesine, and cisplatin in unresectable stage III non-small-cell lung cancer. J. Clin. Oncol. 17, 2692-2699. Huber, R. M., Flentje, M., Schmidt, M., Pöllinger, B., Gosse, H., Willner, J., and Ulm, K. (2006). Simultaneous chemoradiotherapy compared with radiotherapy alone after induction chemotherapy in inoperable stage IIIA or IIIB non-small-cell lung cancer: study CTRT99/97 by the Bronchial Carcinoma Therapy Group. J. Clin. Oncol. 24, 4397-4404. Jemal, A., Bray, F., Center, M. M., Ferlay, J., Ward, E., and Forman, D. (2011). Global cancer statistics. CA Cancer J. Clin. 61, 69-90.

Khuri, F. R., Wu, H., Lee, J. J., Kemp, B. L., Lotan, R., Lippman, S. M., Feng, L., Hong, W. K., and Xu, X. C. (2001). Cyclooxygenase-2 overexpression is a marker of poor prognosis in stage I non-small cell lung cancer. Clin. Cancer Res. 7, 861-867.

Kim, H. T., Han, J. Y., Lee, D. H., Chun, J. H., Lee, H. G., Lee, J. J., Kim, H. Y., Lee, S. Y., and Lee, J. S. (2006). A phase II study of irinotecan plus cisplatin for patients with advanced stage IIIB or IV NSCLC previously treated with nonplatinumbased chemotherapy. Cancer 107, 799-805.

Komaki, R., Liao, Z., and Milas, L. (2004). Improvement strategies for molecular targeting: cyclooxygenase-2 inhibitors as radiosensitizers for non-small cell lung cancer. Semin. Oncol. 31, 47-53.

Kubota, K., Watanabe, K., Kunitoh, H., Noda, K., Ichinose, Y., Katakami, N., Sugiura, T., Kawahara, M., Yokoyama, A., Yokota, S., Yoneda, S., Matsui, K., Kudo, S., Shibuya, M., Isobe, T., Segawa, Y., Nishiwaki, Y., Ohashi, Y., and Niitani, H. (2004). Phase III randomized trial of docetaxel plus cisplatin versus vindesine plus cisplatin in patients with stage IV non-small-cell lung cancer: the Japanese Taxotere Lung Cancer Study Group. J. Clin. Oncol. 22, 254-261.

Langer, C. J., Somer, R., Litwin, S., Feigenberg, S., Movsas, B., Maiale, C., Sherman, E., Millenson, M., Nicoloau, N., Huang, C., and Treat, J. (2007). Phase I study of radical thoracic radiation, weekly irinotecan, and cisplatin in locally advanced non-small cell lung carcinoma. J. Thorac. Oncol. 2, 203-209.

Liao, Z., Komaki, R., Milas, L., Yuan, C., Kies, M., Chang, J. Y., Jeter, M., Guerrero, T., Blumenschein, G., Smith, C. M., Fossella, F., Brown, B., and Cox, J. D. (2005). A phase I clinical trial of thoracic radiotherapy and concurrent celecoxib for patients with unfavorable performance status inoperable/unresectable non-small cell lung cancer. Clin. Cancer Res. 11, 3342-3348.

Lilenbaum, R., Socinski, M. A., Altorki, N. K., Hart, L. L., Keresztes, R. S., Hariharan, S., Morrison, M. E., Fayyad, R., and Bonomi, P. (2006). Randomized phase II trial of docetaxel/irinotecan and gemcitabine/irinotecan with or without celecoxib in the second-line treatment of non-small-cell lung cancer. J. Clin. Oncol. 24, 4825-4832.

Miller, A. B., Hoogstraten, B., Staquet, M., and Winkler, A. (1981). Reporting results of cancer treatment. Cancer 47, 207-214.

Movsas, B., Scott, C., Langer, C., WernerWasik, M., Nicolaou, N., Komaki, R., Machtay, M., Smith, C., Axelrod, R., Sarna, L., Wasserman, T., and Byhardt, R. (2005). Randomized trial of amifostine in locally advanced non-small-cell lung cancer patients receiving chemotherapy and hyperfractionated radiation: radiation therapy oncology group trial 98-01. J. Clin. Oncol. 23, 2145-2154.

Mutter, R., Lu, B., Carbone, D. P., Csiki, I., Moretti, L., Johnson, D. H., Morrow, J. D., Sandler, A. B., Shyr, Y., Ye, F., and Choy, H. (2009). A phase II study of celecoxib in combination with paclitaxel, carboplatin, and radiotherapy for patients with inoperable stage IIIA/B non-small cell lung cancer. Clin. Cancer Res. 15, 2158-2165.

National Cancer Institute. (2006). Common Terminology Criteria for Adverse Events 13.0 (CTCAE). Available at: http:// ctep.cancer.gov/protocoldevelopme nt/electronic_applications/docs/ctc aev3.pdf

Pfister, D. G., Johnson, D. H., Azzoli, C. G., Sause, W., Smith, T. J., Baker, S. Jr., Olak, J., Stover, D., Strawn, J. R., Turrisi, A. T., and Somerfield, M. R. (2004). American Society of Clinical Oncology treatment of unresectable non-small-cell lung cancer guideline: update 2003. J. Clin. Oncol. 2, 330-353.

Takiguchi, Y., Uruma, R., Asaka-Amano, Y., Kurosu, K., Kasahara, Y., Tanabe,
N., Tatsumi, K., Uno, T., Itoh, H., and Kuriyama, T. (2005). Phase I study of cisplatin and irinotecan combined with concurrent hyperfractionated accelerated thoracic radiotherapy for locally advanced nonsmall cell lung carcinoma. Int. J. Clin. Oncol. 10, 418-424.

Tamura, K., Takada, M., Kawase, I., Tada, T., Kudoh, S., Okishio, K., Fukuoka, M., Yamaoka, N., Fujiwara, Y., and Yamakido, M. (1997). Enhancement of tumor radio-response by irinotecan in human lung tumor xenografts. Jpn. J. Cancer Res. 88, 218-223.

Trifan, O. C., Durham, W. F., Salazar, V. S., Horton, J., Levine, B. D., Zweifel, B. S., Davis, T. W., and Masferrer, J. L. (2002). Cyclooxygenase-2 inhibition with celecoxib enhances antitumor efficacy and reduces diarrhea side effect of CPT-11. Cancer Res. 62, 5778-5784.

Yamada, M., Kudoh, S., Fukuda, H., Nakagawa, K., Yamamoto, N., Nishimura, Y., Negoro, S., Takeda, K., Tanaka, M., and Fukuoka, M. (2002). Dose-escalation study of weekly irinotecan and daily carboplatin with concurrent thoracic radiotherapy for unresectable stage III non-small cell lung cancer. $\mathrm{Br}$. $\mathrm{J}$. Cancer 87, 258-263.

Conflict of Interest Statement: The authors declare that the research was conducted in the absence of any commercial or financial relationships that could be construed as a potential conflict of interest.

Received: 11 October 2011; paperpending published: 03 November 2011; accepted: 26 November 2011; published online: 13 December 2011.

Citation: Komaki R, Wei X, Allen PK, Liao Z, Milas L, Cox JD, O'Reilly MS, Chang JY, McAleer MF, Jeter M, Blumenschein GR Jr and Kies MS (2011) Phase I study of celecoxib with concurrent irinotecan, cisplatin, and radiation therapy for patients with unresectable locally advanced non-small cell lung cancer. Front. Oncol. 1:52. doi: 10.3389/fonc. 2011.00052

This article was submitted to Frontiers in Thoracic Oncology, a specialty of Frontiers in Oncology.

Copyright (c) 2011 Komaki, Wei, Allen, Liao, Milas, Cox, O'Reilly, Chang, McAleer, Jeter, Blumenschein Jr and Kies. This is an open-access article distributed under the terms of the Creative Commons Attribution Non Commercial License, which permits non-commercial use, distribution, and reproduction in other forums, provided the original authors and source are credited. 